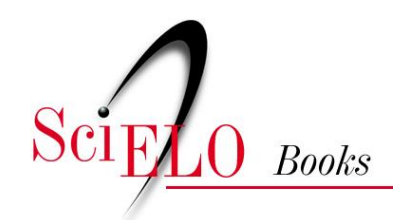

\title{
Feduepb
}

\section{Algumas considerações sobre o Diabo na Divina Comédia}

\author{
Daniel Lula Costa \\ Solange Ramos de Andrade
}

\section{SciELO Books / SciELO Livros / SciELO Libros}

COSTA, DL., and ANDRADE, SR. Algumas considerações sobre o Diabo na Divina Comédia. In MAGALHÃES, ACM., et al., orgs. O demoníaco na literatura [online]. Campina Grande: EDUEPB, 2012. pp. 149-160. ISBN 978-85-7879-188-9. Available from SciELO Books

<http://books.scielo.org>.

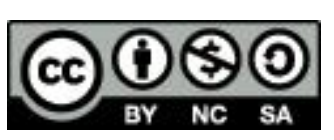

All the contents of this work, except where otherwise noted, is licensed under a Creative Commons Attribution-Non Commercial-ShareAlike 3.0 Unported.

Todo o conteúdo deste trabalho, exceto quando houver ressalva, é publicado sob a licença Creative Commons Atribuição Uso Não Comercial - Partilha nos Mesmos Termos 3.0 Não adaptada.

Todo el contenido de esta obra, excepto donde se indique lo contrario, está bajo licencia de la licencia Creative Commons Reconocimento-NoComercial-CompartirIgual 3.0 Unported. 


\title{
Algumas considerações sobre o Diabo na Divina Comédia
}

\author{
Daniel Lula Costa (UEM) ${ }^{1}$ \\ Solange Ramos de Andrade (UEM) ${ }^{2}$
}

Desde a Antiguidade o cristianismo professa a salvação das almas bondosas e, acima de tudo, cristãs: "pregar era, de fato, definir os contornos da verdadeira religião diante da heresia e da superstição" (BEAULIEU, 2006, p.367). Por meio de grandes conflitos entre numerosas ideias mitológicas ela se estabelece no Ocidente como uma referência religiosa e passa a aumentar seu território religioso por meio de seu discurso e de suas estratégias de profissão: "as armas da Igreja eram mais espirituais" (LE GOFF, 2005, p.275)

O cristianismo se instituiu como explicação para a vida, para a conduta humana e para a morte. O discurso religioso caracteriza-se pela ideia do pós-morte, do supremo e do sobrenatural. Na Idade Média o medo do desconhecido estava presente no cotidiano, o homem medieval reagia aos conflitos e as dificuldades por meio de sua fé, muitas vezes conflituosa entre o desconhecido e a ideia cristã. Esse imaginário medieval confundia-se com as diversas mitologias antigas e a busca por novas explicações.

1 Daniel Lula Costa é Mestrando em História pelo Programa de Pós-graduação em História da Universidade Estadual de Maringá (PPH-UEM). Bolsista da CAPES. Integrante do Laboratório de Estudos em Religiões e Religiosidades (LERR-UEM). E-mail:daniellcosta23@yahoo.com.br

2 Solange Ramos de Andrade é Professora Associada do Departamento de História e do Programa de Pós-Graduação em História da Universidade Estadual de Maringá - PR. Bolsista Produtividade em Pesquisa pela Fundação Araucária de Apoio ao Desenvolvimento Científico e Tecnológico do Estado do Paraná. Coordenadora do Laboratório de Estudos em Religiões e Religiosidades (LERR-UEM). E-mail: sramosdeandrade@gmail.com 
O Além foi o tema de maior repercussão no medievo, saber a trajetória da alma após a morte é uma ideia confortante e interessante. "O além é um dos grandes horizontes das religiões e das sociedades. A vida do crente transforma-se quando ele pensa que nem tudo fica perdido com a morte." (LE GOFF, 1981, p.15)

A própria estrutura das cidades estava ligada à mentalidade da relação entre o vivo e o morto. Os cemitérios estavam mais próximos do solo sagrado, ao lado das Igrejas e os rituais como a preparação do corpo para ser enterrado e a confissão antes da morte mostram a extrema influência do cristianismo no imaginário ocidental. Estas formas de conduta estão ligadas a preocupação do vivo com a sua alma e com o seu destino após a morte, "O quadro de todas essas práticas é a comunidade local dos vivos e dos mortos, a paróquia, o par indissociável da igreja e do cemitério no próprio centro da aldeia ou do bairro." (SCHMITT, 1999, p.145)

De certa forma o próprio conhecimento do pós-morte não era em seu todo confortante. Do ano mil ao século XIII, um dos ambientes descritos no medievo caracterizou-se pelo medo, pela punição, pelo pecado, pelos seres monstruosos e pelo Diabo. Este ambiente foi muito citado no medievo e ficou conhecido como Inferno. Dos três ambientes do pós-morte cristão (Inferno, Purgatório e Paraíso) este foi o que mais marcou o imaginário e a conduta do fiel, pois uma de suas caracteristicas era estabelecer a punição pelo ato do pecado. Ao conhecer a punição e o mal que habitava este local o cristão buscava levar uma vida de paz e bondade.

Terrificantes ou tranqüilos, a morte e os mortos estão igualmente presentes muito concretamente em um grande número de relatos para dar esperança (mostrando, com o apoio de exemplos, que até o último suspiro nunca é tarde demais para arrepender-se dos pecados) ou para despertar o medo (descrevendo com grande luxo de detalhes os castigos infernais). (SCHMITT, 1999, p.144)

Dessa forma nos deparamos neste momento com as seguintes perguntas: Quem é o Diabo? Como ele é descrito? Por meio destas perguntas reconstruiremos este ser de acordo com algumas das diversas imagens e discursos que relatavam ou descreviam o Diabo como rei do reino do mal absoluto cristão, principalmente buscando entender a representação do Diabo na obra magna de Dante Alighieri: a Divina Comédia. 
Antes de conhecermos o Diabo dantesco devemos entender alguns empecilhos como: o mito de origem do reino do mal cristão, as imagens de Lúcifer que foram pensadas e como seu mito foi construído. A existência do Inferno é resultado de um conflito celestial, de acordo com a mitologia cristã, um dos anjos de Deus rebelou-se contra seu Senhor com o desejo de ser como seu criador ou até mesmo melhor que ele. Ao descobrir está ideia recorrente na mente de um de seus anjos, Deus acaba punindo-o, e também aqueles que o apoiaram.

Estava presente no imaginário medieval que do Paraíso celestial o anjo foi lançado à Terra, sua queda foi tão forte que modificou a própria geografia do planeta. De acordo com está interpretação o Inferno é criado como um grande buraco em formato de cone que se prolonga até o centro da Terra, onde está o anjo caído, conhecido também como Lúcifer.

Lúcifer é um dos nomes dados a personificação do mal na religião cristã. Não se sabe ao certo a própria origem deste nome, alguns historiadores atribuem a esta denominação uma interpretação do livro de Isaías. Na realidade o termo Lúcifer não seria um nome, mas um adjetivo que significa: "o que leva a luz" (LINK, 1998). Ao analisarmos o próprio contexto desta afirmação, contida no livro de Isaías, notamos que o termo poderia ter qualificado a estrela Vênus, uma das primeiras a aparecer ao anoitecer; e que Isaías teria utilizado está palavra para se referir a um rei tirânico que havia caído (LINK, 1998).

No século XIII, ao escrever a Divina Comédia, o poeta florentino, Dante Alighieri, denomina o ser maligno do Inferno como Lúcifer, ou seja, para o poeta a denominação Lúcifer e Diabo são atribuídas ao mesmo ser (LINK, 1998), consequentemente, significam a mesma coisa. Mas como isso acontece?

A atribuição das ações malignas e de tudo aquilo que é tido como mal são tidas como obras do Diabo, ou seja, podemos deduzir que o Diabo é o próprio mal. As denominações Diabo e Lúcifer referindo-se ao ser maligno não estão nas Escrituras (LINK, 1998). No entanto devemos investigar a apropriação deste termo pelo cristianismo e pelos fiéis para que, posteriormente, significasse a personificação do mal.

O Diabo possui inúmeros nomes, estes vão de Satã, Demônio, Rei do Inferno, até chegar a Lúcifer. Como observamos, o termo Diabo não 
está presente no Antigo Testamento, portanto, como o próprio Link descreve: "fora introduzido pelos judeus alexandrinos: ao verterem o Antigo Testamento para o grego, traduziram o satan hebraico para o grego diabolos." (LINK, 1998, p.24). A palavra Diabo provém de três línguas diferentes: hebreu, grego e latim, sendo respectivamente; satan, diabolos, diabolus.

O Antigo Testamento, mais precisamente, o Livro de Jó contribuiu para a história do Diabo e, também para a atribuição da associação angelical que a ele será atribuída na arte do século IX. "Deus está satisfeito com seu servo Jó e o louva, mas eis que se adianta o Satan (= 'hostilizar, acusar, caluniar'), um dos 'filhos de Deus', isto é, um anjo." (NOGUEIRA, 1986, p.8)

Mas o que significa Diabo? De acordo com a maioria dos dicionários de figuras simbólicas, o termo Diabo significa: caluniador, provocador de discórdia, acusador. Averiguamos o significado da palavra Diabo em dois dicionários de símbolos. De acordo com Udo Becker, o termo Diabo significa:

[gr. Diabolos= caluniador, provocador de discórdia; hebr. Satã]. Segundo a doutrina cristã, trata-se de $>$ anjos que se rebelaram contra Deus, especialmente o mais elevado entre eles, Lúcifer, que seduziu o primeiro casal humano ao pecado desde então é o "príncipe do mundo". (BECKER, 2007, p.88)

Já, de acordo com o Chevalier e Gheerbrant Diabo significa:

El maligno es el símbolo de lo malvado. Vistase de gran señor o gesticule sobre los capiteles de las catedrales, tenga cabeza de boque o de camello, los pies ahorquillados, cuernos, pelo por todo el cuerpo, poco importan las figuras, él no anda nunca escaso de apariencias, pero es siempre el Tentador y el Verdugo. (CHEVALIER; GHEERBRANT, 1986, p.414, negrito nosso)

Notamos que o primeiro dicionário busca a explicação na própria etimologia da palavra, enquanto o segundo analisa o próprio termo produzido pelo imaginário, sendo ambos por este motivo necessários. Esta 
breve explicação nos mostrou as várias denominações do Diabo, mas qual seria a sua forma?

De acordo com Link, o Diabo é uma máscara sem rosto (LINK, 1998); título que ele atribuiu a seu livro. A explicação é que diferente das figuras cristãs como, por exemplo, Jesus Cristo e Maria, o Diabo não possui uma imagem estabelecida e institucionalmente aceita. Dessa maneira o termo e o próprio imaginário carregam inúmeros modelos do que seria a figura fisica de Lúcifer. Perante os séculos notamos uma imagem do Diabo muito variável, ela passa por diversas metamorfoses, de uma figura angelical para a de um monstro grotesco.

A própria associação de Deus como luz, brilhante e iluminado possibilita uma contraposição do Diabo, seu maior adversário, como representante da escuridão, do preto e obscuro. Lúcifer é o adversário de Deus e, portanto, é tudo aquilo que é oposto a Deus, de acordo com Chevalier e Gheerbrant, o Diabo é: "centro de noche, por oposición a Dios, centro de luz.” (CHEVALIER; GHEERBRANT, 1986, p.414). No século IX, Lúcifer passa a ser representado como um anjo negro, escuro e nu.

Por que o Diabo é preto? Seu negrume contrastava com a beleza branca dos anjos. O preto representa o mal e a poluição. Satã sentado em seu trono no Inferno é sempre preto. Quando cai do céu, é preto o mais das vezes. Talvez o negrume do Diabo tenha relação com os deuses egípcios e núbios. (LINK, 1998, p.63, negrito nosso)

$\mathrm{Na}$ maioria das vezes o Diabo é representado como um anjo nu e pintado em tinta preta. A nudez pode ser tanto uma representação da tentação ou a ideia de um ser não social, ou seja, que não vive mais em sociedade desde a sua expulsão do Paraíso celestial. "Nudez tornou-se desnudamento, e desnudamento tornou-se degradação e humilhação, um sinal de ser enxotado como um louco ou um animal [...]" (LINK, 1998, p.67).

O Diabo não era representado de forma homogênea pelos pintores e escritores, eles não sabiam como construir ou encarar o anjo caído. Muitas pinturas anteriores ao século XVI colocam o Diabo em comparação com o Deus Pã; um sátiro metade homem e metade animal, com cascos, chifres, orelhas pontudas e barda. Não se sabe o porque os sátiros e o próprio Deus Pã foram transformados em demônios e, muitas vezes, no próprio Diabo. 
Constatamos que a figura do Diabo passou por diversas transformações que culminaram em diversas associações ao mal, ao grotesco e aos seres mitológicos. Estas intenções de entender o Rei do Inferno, pertencentes às diversas obras de arte do período medieval, à literatura e ao discurso cristão possibilitaram que o poeta florentino Dante Alighieri construísse outra versão do Diabo cristão; verificaremos a forma e a representação deste monstro na Divina Comédia.

\section{O Lúcifer dantesco}

O Diabo, como vimos, possui diversos nomes e isto também ocorre na obra de Dante, na qual encontramos a nomenclatura: Dite, Lúcifer e Satã. Este ser possui características grotescas, medonhas e monstruosas, mas antes de verificarmos a personificação do Diabo na Divina Comédia faz-se necessário uma breve apresentação do poeta, Dante Alighieri e de sua obra magna.

O poeta florentino nasceu na cidade de Florença em 1265 (FRANCO JUNIOR, 2000). Não possuímos grandes informações sobre a sua infância e adolescência, mas perante algumas biografias do poeta e de acordo com as suas obras, verificamos que ele frequentou instituições de ensino e dedicou-se ao conhecimento. Dante foi um poeta preocupado com o seu mundo e com a sua cidade natal, mas acima de tudo ele amou Beatriz.

O poeta conheceu Beatriz aos nove anos de idade, e apaixonouse. Não sabemos ao certo se Dante encontrou-se muito com a dama, pois foi obrigado a casar-se com Gema Donatti por meio de um acordo matrimonial (DISTANTE, 2008). Dessa forma o amor de Dante por Beatriz não passou de um sentimento reprimido. Beatriz morreu em 1290 (FRANCO JUNIOR, 2000), e o amor entre ela e o poeta não foi concretizado.

Por meio de desentendimentos políticos, Dante Alighieri foi exilado de sua cidade natal. Foi durante este exílio que ele dedicou-se integralmente a poesia, e escreveu sua obra magna Divina Comédia. O objetivo central deste poema é possibilitar que Dante reencontre seu grande amor, Beatriz. Como eles não puderam ser felizes em suas vidas terrenas, Dante pensou em amá-la na vida após a morte. Dessa forma o protagonista de sua obra é 
ele mesmo, ainda vivo que peregrinará pelos ambientes do pós-morte cristão para encontrar a alma de Beatriz que foi destinada ao Paraíso celestial.

O poema é dividido em três partes: o Inferno, o Purgatório e o Paraíso. Cada uma delas possui 33 cantos, com exceção do Inferno que possui 34, sendo que o primeiro é uma introdução para toda a obra. As estrofes são compostas por três versos, em tercetos encadeados (DISTANTE, 2008). O número três é muito presente na estrutura do poema; uma referência a Santíssima Trindade: Pai, Filho e Espírito Santo.

Para cumprirmos com o nosso objetivo focaremos na primeira parte do poema, o Inferno. Ele é dividido em nove círculos infernais, cada qual diferenciado pelas punições, pelos pecados, pelos demônios e pela estrutura ambiental. O poeta organizou e criou uma geografia para o Inferno cristão, conforme lemos o poema conseguimos pensar imageticamente como Dante e o imaginário medieval conceberam o Inferno cristão.

Ainda segundo este imaginário, o Inferno originou-se próximo a cidade de Jerusalém. A queda de Lúcifer deu forma ao ambiente e o estruturou em círculos. O primeiro círculo é o Limbo, daqueles que não foram batizados ou nasceram antes de Cristo. O segundo círculo é o dos luxuriosos; no terceiro estão os gulosos; no quarto círculo estão os avaros e pródigos; no quinto encontramos os danados pela ira; no sexto círculo estão os hereges; no sétimo os violentos; no oitavo os fraudulentos; no nono e último círculo, os traidores.

A figura central para nossa análise encontra-se no nono círculo do Inferno, o círculo dos traidores e também, o último círculo, onde o peso da alma ganha o seu ápice, pois para Dante a traição era o pior dos pecados. Este círculo é localizado no centro da Terra e é dividido em quatro partes: Caina, Antenora, Ptoloméia e Judeca. Este círculo tem uma peculiaridade, ele é frio e seu lago Cocito está congelado, onde estão as almas traidoras. Lúcifer está na última parte onde mastiga os traidores: Judas, Brutus e Cássio.

A própria imagem que Dante transmite de Lúcifer é algo um tanto diferente. Devemos compreender que a partir do ano mil o Diabo estava solto, "O Inimigo e miríades de demônios vagavam por toda parte, tentando e corrompendo, explorando cada fraqueza e desejo" (NOGUEIRA, 1986, p.35). Ao lermos e verificarmos o Diabo na Divina 
Comédia percebemos que a intenção de Dante não é mostrar um ser livre que vaga pelo seu reino assim como anda pela Terra, mas uma figura que em seu lar é presa, medonha e grotesca.

Lúcifer ‘já foi belo como hoje é feio’, lembrou Dante a seus leitores, mas somente a feiúra e maldade de Satã estiveram na mente dos crentes, pensadores, escritores e artistas durante mais de mil anos. Até mesmo Botticelli, amante da beleza, desenhou uma fera repulsiva para ilustrar o Lúcifer de Dante. (LINK, 1998, p.31)

No século XI e XII a arte constrói o Diabo com barba, cascos e pelos, Muchembled (2001) afirma que o Diabo passa a tornar-se bestial a partir do século XIII. A herança das imagens do demoníaco ainda estão presentes e transformam o Diabo em um ser animalesco, grotesco, com unhas grandiosas, uma expressão tenebrosa e dentes horríveis, como o oposto dos anjos.

Ele deixa sua abstração sem forma para tornar-se devorador de homens, uma besta do Apocalipse. As faces de um homem com barba, antes atribuídas ao sátiro, orelhas pontudas e olhar fulminante marcam a figura do Diabo neste período. Ele causa medo às elites da fé e se sobrepõe sobre os cristãos mais simples que antes o viam como uma abstração sem forma e agora vinculam as imagens das catedrais, do teatro e das obras de arte ao modelo de Diabo.

O diabo ainda é buscado, ou melhor, os homens que o imaginam hesitam entre a lição grotesca que agrada a muitos e uma definição mais assustadora nascida de uma meditação teológica desenvolvida desde Gregório, o Grande. A Acentuação de traços negativos e maléficos dos demônios pode ser realmente assinalada a partir do século XIV [...] (MUCHEMBLED, 2001, p.34)

Dante Alighieri descreve a figura de Lúcifer no final do século XIII e início do XIV. A sua interpretação é baseada no monstruoso, na ideia do anjo caído possuidor de asas que não são mais belas e angelicais, mas grossas, negras e em formato igual às asas de morcego. O Lúcifer dantesco é descrito no canto 34, último canto do Inferno, Dante apresenta primeiramente as faces do Diabo: 
Mas foi o meu assombro inda crescente

quando três caras vi na sua cabeça:

toda vermelha era a que tinha à frente,

e das duas outras, cada qual egressa

do meio do ombro, que em cima se ajeita

de cada lado e junta-se com essa,

branco-amarelo era a cor da direita

e, a da esquerda, a daquela gente estranha

que chega de onde o Nilo ao vale deita.

(ALIGHIERI, 2008, p.226)

Nesta descrição, Lúcifer possui três faces e cada uma delas difere-se pela cor. A do meio é vermelha, a da esquerda é negra e a da direita é branco-amarelada. Diversos historiadores buscam explicações para a distribuição de cores das faces do Diabo dantesco, mas as suas interpretações ainda são incertas. De acordo com Russel (2003), diversas são as teorias sobre as cores aqui analisadas e uma delas foi a de Freccero que as analisou da seguinte forma:

Ele começa a explicação com Lucas 17:6, no qual Cristo diz que com fé profunda o bastante a pessoa poderia pedir para uma amoreira se mover e ela se moveria. Santo Ambrósio usou a amoreira como um símbolo do Diabo, pois da mesma maneira que sua fruta começa branca, amadurece e fica vermelha, e então fica preta, assim o Diabo começa glorioso e branco, brilha vermelho no poder dele, e então fica preto com o pecado. Mas Agostinho usou a amora tricolorida como um símbolo da cruz. E Ubertino de Casale descreveu vexilla de Cristo como colorido da mesma maneira. O que Dante fez foi reunir a cruz, o Diabo e as três cores. (RUSSEL, 2003, p.224)

Depois de descrever a cabeça de Lúcifer, Dante descreve o seu corpo bestial. Podemos identificar a figura de um anjo caído, o Diabo dantesco é possuidor de três pares de asas de morcego em comparação as asas dos Serafins que no Paraíso dantesco possuem três asas brancas e grandiosas; o branco e iluminado em oposição ao escuro e macabro. Segundo Link 
(1998), a atribuição de asas de morcego ao Diabo não é algo originado em Dante, algumas teorias apontam que ele pode ter se baseado nas pinturas das catedrais, principalmente na pintura de Giotto que desenhou os demônios com asas de morcego.

$$
\begin{aligned}
& \text { Um par de grandes asas acompanha } \\
& \text { cada uma, com tal ave consoantes: } \\
& \text { - vela de mar vira eu jamais tamanha- } \\
& \text { essas, sem penas, semelhavam antes } \\
& \text { às dos morcegos, e ele as abanava, } \\
& \text { assim que, co' os três ventos resultantes, } \\
& \text { as águas de Cocito congelava. } \\
& \text { (ALIGHIERI, 2008, p.227 ) }
\end{aligned}
$$

O Lúcifer dantesco é um monstro grandioso, com três faces que diferem-se não só pelas cores, mas pelos danados que mastiga. Em cada uma das bocas são mastigados os pecadores: Judas, Brutus e Cássio. Dante narra está cena de uma maneira que provoca no leitor a sensação de horror e desgosto, algo repugnante e bestial. Além das faces e dos pares de asas, Dante apresenta a bestialidade do Diabo cobrindo seu corpo grandioso com pelos.

$$
\begin{aligned}
& \text { Ao chegarmos à altura da junção } \\
& \text { da coxa ao tronco do gigante averno, } \\
& \text { meu guia, dando sinais já de exaustão, } \\
& \text { reverteu o corpo, sem perder governo } \\
& \text { do pelame, e seguiu, ora subindo, } \\
& \text { dando-me o senso de voltar pro inferno. }
\end{aligned}
$$$$
\text { (ALIGHIERI, 2008, p.228) }
$$

O corpo felpudo e as suas asas são uma demonstração das figuras bestiais e do desconhecido, uma associação das características animalescas ao Diabo. O Rei do Inferno é apresentado de diversas formas e não carrega uma representação ideal sendo muitas vezes o oposto daquilo que é tido como bom pela religião cristã. O Diabo da Divina Comédia reina no Inferno e carrega o peso de todos os pecados, sendo por isso a ponta do cone invertido deste ambiente. Ele é grotesco e animalesco, a sua queda do Paraíso celestial o deformou: 
Dante pretendeu apresentar Lúcifer vazio, tolo, e desprezível, um contraste fútil para a energia de Deus. Dante viu o mal como negação e teria pensado o Diabo de Milton muito mais ativo e efetivo. A ausência formal de Lúcifer de grandes áreas da Comédia e do próprio Inferno indica o acorde de Dante com a teologia escolástica, limitando o papel do Diabo. (RUSSEL, 2003, p.217)

O Diabo passa a ser transformado na besta primordial, não apenas na besta física retratada na literatura e na arte, mas também na besta que produz atos monstruosos e animalescos, atos que todo ser humano teria de evitar para não deixar que o próprio Diabo o possuísse. Dessa forma a besta passa a ser considerada um animal possuído pelo demônio, cujas ações seriam conduzidas para a anarquia, matança e carnificina, o mais longe possível da luz e de Deus. O lobisomem e todos os outros seres que aterrorizavam as civilizações passam a ser considerados servos do Diabo, sendo ele retrato dessa maneira, com rabo, pêlos, garras, cauda, asas e cuspidor de fogo, muitas vezes confundido ou idealizado como um dragão (MUCHEMBLED, 2001).

O Lúcifer dantesco é apresentado de uma forma medonha, monstruosa, grotesca e horrorosa, uma oposição ao belo, à luz, ao Cristo, aos anjos e a Deus. A partir do século XIII e início do XIV, o Diabo é associado às bestas, ele passa de um ser meio humano com características animalescas para se constituir na própria imagem do monstro e do desconhecido que gera e transmite medo da mesma forma que é grotesco e medonho. 


\section{Bibliografia}

ALIGHIERI, D. A Divina Comédia: Inferno. 1ª Edição (1998). Prefácio por Carmelo Distante, tradução e notas por Italo Eugenio Mauro. Edição bilíngue. 15ª Ed. São Paulo: Editora 34, 2008.

BEAULIEU, M. P. Pregação. In: LE GOFF, J; SCHMITT, J. Dicionário temático do ocidente medieval. São Paulo: EDUSC, 2006. p.367-376.

BECKER, U. Dicionário de Símbolos. São Paulo: Paulus, 2007.

CHEVAlIER, J; GHEERBRANT. Diccionario de los Símbolos. Barcelona: Editorial Herder, 1986.

DistAnTE, C. Prefácio. In: ALIGHIERI, D. A Divina Comédia: Inferno. São Paulo: Editora 34, 2008. p. 7-17.

FRANCO JUNIOR. H. Dante: o poeta do absoluto. São Paulo: Ateliê Editorial, 2000

LE GOFF, J. A Civilização do Ocidente Medieval. São Paulo: Edusc, 2005

LE GOFF, J. O nascimento do purgatório. Lisboa: Estampa, 1981.

LINK, L. O Diabo: A máscara sem rosto. São Paulo: Companhia das Letras, 1998.

MUCHEMBLED, R. Uma história do Diabo: séculos XII-XX. Rio de Janeiro: Bom Texto, 2001.

NOGUEIRA, C.R.F. O Diabo no imaginário cristão. São Paulo: Editora Ática, 1986.

RUSSEL, J. B. Lúcifer: O Diabo na Idade Média. São Paulo: Editora Madras, 2003.

SCHMITT, J. C. Os vivos e os mortos na sociedade medieval. São Paulo: Companhia das Letras, 1999.

\section{Imagem:}

Um Diabo Lógico, Salvador Dalí. Disponível em http://extra.globo. com/incoming/5661795-dec-76d/w448h673-PROP/dali-divina-comedia. jpg, consultado em 07/10/2012. 